\title{
Smart Cities and Smart Tourism: What Future Do They Bring?
}

\author{
Ana Matos ${ }^{1}$, Bruna Pinto ${ }^{1}$, Fábio Barros ${ }^{2}$, Sérgio Martins ${ }^{2}$, \\ José Martins ${ }^{3,4}$, and Manuel Au-Yong-Oliveira ${ }^{1,5(\bowtie)}$ \\ ${ }^{1}$ Department of Economics, Management, Industrial Engineering and Tourism, \\ University of Aveiro, 3810-193 Aveiro, Portugal \\ \{anaclaudiamatos, pintobruna, mao\}@ua.pt \\ 2 Department of Electronics, Telecommunication and Informatics, \\ University of Aveiro, Aveiro, Portugal \\ \{fabiodaniel, sergiomartins8\}@ua.pt \\ 3 INESC TEC and University of Trás-os-Montes e Alto Douro, \\ Vila Real, Portugal \\ jmartins@utad.pt \\ ${ }^{4}$ Polytechnic Institute of Bragança - EsACT, Mirandela, Portugal \\ ${ }^{5}$ GOVCOPP, Aveiro, Portugal
}

\begin{abstract}
We have sought to understand the current state of the art on smart tourism and on smart cities. Furthermore, we have sought to understand community awareness and the will to embrace innovation, as they are decisive factors to acquire base knowledge and overcome barriers in (soon to be) overpopulated cities and for those who are looking for a limited time culture experience - known as tourists. We live in an age where technology is increasingly present in our lives and provides us solutions to societal problems. Problems such as traffic, infrastructure and natural resources management, or even increasing citizens' participation in governance, bringing them closer to decision-making. The objective is to understand the current level of people's knowledge about the impact that technologies have on the society in which we live and their perception of the usefulness in solving these same problems. Therefore, an anonymous questionnaire was carried out (176 valid answers were received), as well as a focus group with two experts on the Smart Cities subject. What future is brought by those who live and breathe technology? Are people willing to accept a paradigm shift?
\end{abstract}

Keywords: Smart cities · Smart tourism - Smart guides · Technology • Sustainability

\section{Introduction}

Smart technologies reach into nearly every aspect of life nowadays, although they are often unnoticed by users and taken for granted most of the time. Cities and tourism are not an exception.

Today, cities are experiencing a severe resource crisis since the number of people living in a city far outnumber the rural population. Thus, it is not possible to continue 
managing cities as they were managed in the last century. It is therefore necessary to find medium- to long-term alternatives to this new reality. As such, the concept of "smart city" arises, which is defined by the use of technology to improve urban infrastructure and make urban areas more efficient while improving the quality of life for their inhabitants. Studies $[8,10]$ consider the existence of six essential pillars in a smart city; smart economy, smart mobility, smart environment, smart people, smart governance and smart living [10].

Smart tourism is one sub category of the smart cities' pillars. It is included within smart living and described as:

"It responds to the requirements of the present global and mobile elites by facilitating access to tourism and hospitality products, services, spaces and experiences through Information and Communication Technology based tools and where a healthy social and cultural environment can be found through a focus on the city's social and human capital. On the other hand, it also implements innovative and entrepreneurial businesses and fosters the interconnectedness of businesses" [16].

This concept is particularly relevant in the Portuguese economy, since tourism is one of the most important sectors of the country, represents more than $5 \%$ of the national Gross Domestic Product [3] and is one of the strategic activities of a developing country. Today's tourist is increasingly dependent on information and communication technologies, growing more demanding and informed, looking forward to new emotions and a new variety of experiences and creating new trends of consumption.

The increase in mobile computing and the popularization of mobile devices has enabled the development of innovative applications in several areas such as smart guides for tourism. Being a sub-category of smart tourism, these suggest personal and more relevant feedback according to the preferences and location of their users. Thus, it aims to replicate a human tourist guide.

To better understand the awareness level and the kind of challenges to be faced in the Portuguese community, on the topics of both smart cities and smart tourism, a questionnaire was publicly launched online, and a focus group meeting was performed with experienced people in the technology field. This allowed for the development and structuring of the current article, to provide relevant insights on what the future holds.

\section{Literature Review}

\subsection{Smart Cities}

According to data provided by World Urbanization Prospects [11, 13, 14], the majority of people currently reside in cities, especially since 2010 [14]. The trend is to increase, with cities being prepared for this new reality. As mentioned by Mitchell [15], the infrastructure of cities faces difficulties due to the fact that more than half of the world population lives in cities, thus it is necessary to find solid long-term solutions; in addition, cities cannot continue to be managed as they used to. According to the United Nations $(U N)$, urban populations will grow by more than 2 billion people over the next 40 years [15] and may become less attractive if there is excessive, untidy construction and no spatial planning, which will lead to social, environmental, energy efficiency, 
transport, and public and private service problems [15]. Besides that, cities only represent $2 \%$ of the Earth's surface, but its inhabitants consume more than $3 / 4$ of the world's natural resources and produce more than $60 \%$ of all carbon dioxide [24]. Hence, there is a need for changes in infrastructure, in the distribution of goods and services, as well as regarding people's overall concern for environmental sustainability.

Accordingly, there comes the concept of "smart city" as a solution to these problems. This concept involves sustainability, energy, waste and traffic management, integration between public systems, and provision of services to the entire population, such as education, health, transportation and energy [8, 10]. All these aspects must be managed in an integrated and intelligent way in order to create synergies aimed at improving the quality of life of the residents while creating efficiency in the services of a given city. Moreover, smart cities also focus on the future, emphasizing the importance of resource and sustainability application for future generations [8].

According to Hollands [11, p. 10], there are four factors that have dominated the different designs and projects of smart cities in implementation around the world, and they are:

- "Focus on information and communication technologies and network infrastructures";

- "Market-induced urban development, with cities shaped by large multinational corporations";

- "Emphasis on technology intensive industries";

- "Concern about environmental sustainability, including energy issues".

The use of technologies is a means for the management of intelligent cities. However, it is not only the adoption of intelligent systems and other technologies that transform a city into a smart city; it is necessary to maintain a certain level of cooperation between technologies, management and improvement of a social economic system, according to Blanco [15]. Information and Communication Technologies (ICT) should be used as a new central nervous system potentiator for the management of smart cities, state Gupta and Toppeta [15]. It is also necessary for citizens to interact with governance in order to find solutions to the challenges large urban areas face, improving the quality of life and respecting the environment.

The report of the University of Technology in Vienna, the University of Ljubljana and the University of Technology in Delft, focused on the development of a ranking of medium-sized smart cities $[8,10]$, considers the existence of six essential pillars in a smart city (as illustrated in Fig. 1): Smart Economy, Smart Mobility, Smart Environment, Smart People, Smart Governance and Smart Living [10].

Smart economy refers to the economic competitiveness of cities, integrating issues associated with innovation and the emergence of new services that lead to the growth and development of the economy. The local accessibility of cities and the ICT network are the main components of smart mobility, such as traffic reduction and the adoption of electric transport with benefits related to $\mathrm{CO}_{2}$ emissions. The smart environment is defined by the attractiveness of natural conditions, environmental protection and resource management, such as waste, water and energy management in order to achieve more efficiency [10]. Smart people relate to the degree of qualification of human resources, with the openness and level of social interactions [10]. Well-informed and 


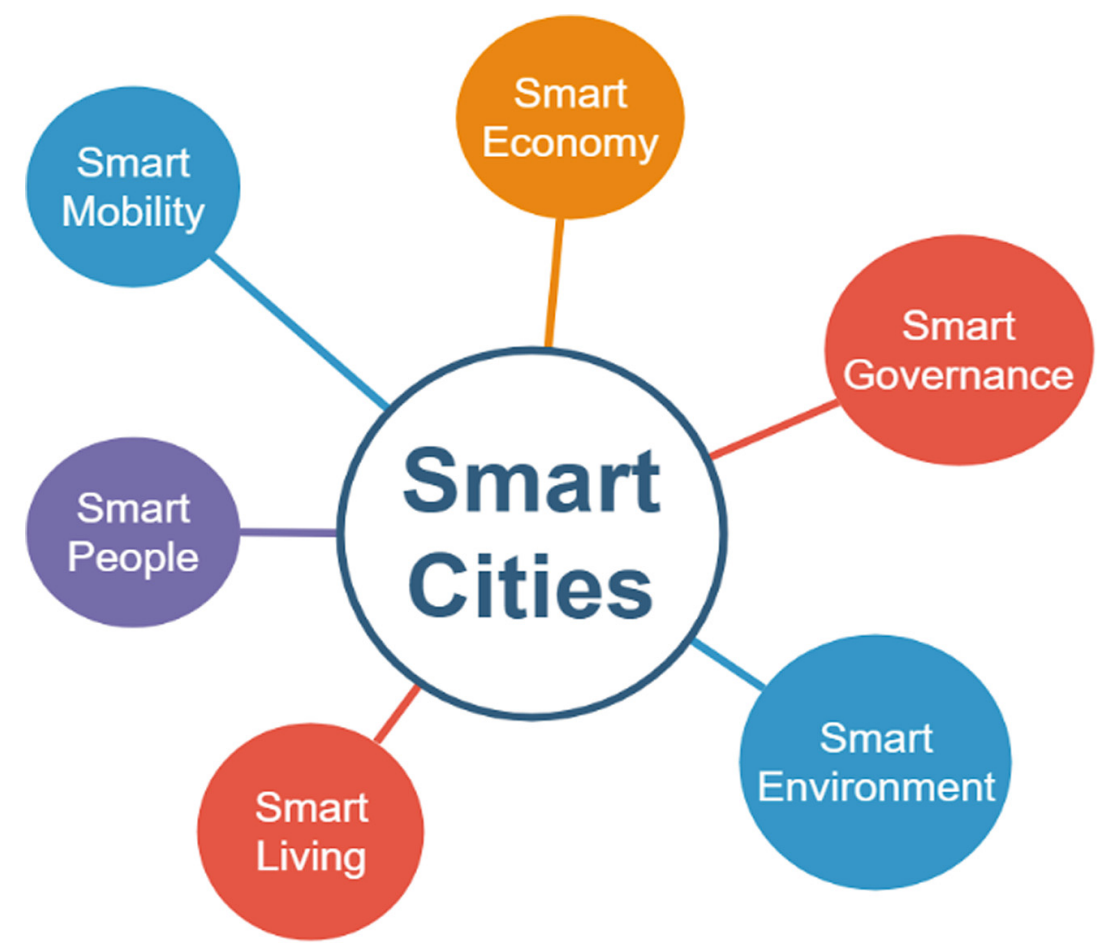

Fig. 1. The six pillars of Smart Cities (based on [8]).

prepared people to deal with the city in an "intelligent" way are essential to achieve the desired efficiency in the implementation of those systems. Smart governance, on the other hand, encompasses aspects related to public participation, services provided to citizens, the functioning of the public administration and greater interaction between citizens and governance. Finally, the intelligent way of life integrates several issues related to the quality of life, such as culture, health, safety, tourism and housing [10].

\subsection{Smart Cities in Europe}

A study was performed on smart cities in Europe, carried out by the Policy Department A: Economic and Scientific Policy of European Parliament, whose analysis is based on the alignment between the objectives and characteristics of each city's project portfolio and the Europe 2020 objectives [9].

Initially, the 468 EU-28 cities with more than 100,000 inhabitants were considered. Through a research process, the level of smart city activity present in each selected city was studied. Based on this initial analysis, 240 EU-28 cities with verifiable smart city activity were identified and from this group, a sample of 50 smart city initiatives were examined in 37 cities. Within this sample, stakeholders, funding and scalability of the initiatives were observed. To explore the relationship between intelligent cities and Europe 2020, relevant evidence was gathered in a structured panel, but the sample of cities used was restricted to 20 , due to data limitations. Afterwards, a quantitative survey was carried out to analyse the alignment between smart city initiatives within the sample of 20 cities and Goals of the Europe 2020 Strategy. Finally, a restraint was made on a range of innovative implementation strategies in the six major cities that run 
the smartest city projects to identify cross-cutting themes and potentially replicable smart city solutions [9].

The main conclusions drawn from this study were as follows [9]:

- In 2011, 240 of the 468 EU-28 cities with at least 100,000 inhabitants (51\% of the total) had at least one smart city feature and can therefore be classified as smart cities;

- There are more small smart cities than big ones; also, smart cities can be found in all size categories and in most EU-28 countries;

- Larger cities tend to have better-structured projects, with at least one fully launched or implemented initiative;

- The most common of the six features are intelligent environment and intelligent mobility, present in $33 \%$ and $21 \%$ of the initiatives, respectively. Each of the other four characteristics is addressed in approximately $10 \%$ of smart cities;

- The size of the city is clearly positively correlated with the number of smart city initiatives;

- Smart living initiatives are found across the EU-28, while initiatives focused on other features are less evenly distributed;

- Smart governance and mobility projects are found mainly in Northern Europe.

\subsection{Portugal and Smart Cities}

Portugal, although not one of the most advanced countries in Europe in this area, already integrates several projects of smart cities.

The latest project, to be implemented in the city of Aveiro, is a smart bus which, in addition to driving itself, also allows access to the Ultra TV content management platform, developed by Altice Labs in partnership with the University of Aveiro [5]. This project also counts on the participation of Ericsson, CarMedia and EasyMile [5]. The bus accommodates six people and uses 5G technology in conjunction with artificial intelligence. The future objective is for passengers to be able to engage in leisure or professional activities during their travels [5].

Another project that is under implementation in Portugal within the scope of smart cities is the Sharing Cities programme [6,7], which has three pilot cities in Europe, Lisbon being one of these cities. The project seeks to develop affordable solutions that result in commercial provisions with high market potential for smart cities. It bles citizen involvement and cooperation at a local level, enhancing trust between cities and citizens. The changes taking place in the capital of Portugal are to the extent of building rehabilitation, shared electric mobility services, energy management systems, smart lighting poles and an urban sharing platform involving citizens. The goal is that by the end of the project, the changes will extend to the rest of Europe [6].

\subsection{Smart Tourism}

Smart tourism is one of the characteristics of smart cities and an important part of the six pillars lying at the base of this concept; considering that tourism is an important sector in the economy of many countries, even of primary importance in some cases, 
smart tourism can support sustainable development tourism and has the potential to be of impact in tourist destinations [21, 25].

"A smart destination is an innovative tourist destination, consolidated on a stateof-the-art technological infrastructure that guarantees the sustainable development of the tourist territory, accessible to all, which facilitates interaction and integration of the visitor with the environment and improves the quality of their destination experience" Stated by Segittur [22, p. 1].

Gordon Philips defined smart tourism as "simply taking a holistic, longer term and sustainable approach to planning, developing, operating and marketing tourism products and businesses". Additionally, smart tourism is modelled by two main techniques [12]:

- Smart searching and usability. To manage research and access content;

- Smart marketing techniques. Used to segment clients to deliver personal and customized feedback.

Another concept of smart tourism emerged from the Organization for Smart Tourism in the United Kingdom and was formulated by Jannie Germann Molz, who identified a relation between smart tourism that links digital mobility to create more intelligent and sustainable connections between tourists and their destination [12].

Mobile technology seems to have accelerated this trend further through the pursuit of information, communication, social networks, as well as mobility-related features to help travellers wherever they might go [21].

\subsection{Smart Guides for Smart Tourism}

Smart guides for tourism are applications that, using the tourist's location and preferences, provide services that are customized and appropriated to the environment in which they are located, such as nearby places and locations that suit certain areas of interest - monuments, historical and cultural areas. These guides aim to mimic the human tourist guide through building relationships between knowledge-based systems, looking to provide a professional service that best meets customers' needs and the desire of gaining sufficient information and an objective understanding of the places visited together, adding value to the tour and raising the level of satisfaction regarding the overall experience [1].

Ergo, it may be stated that today's tourism is close to the concept of "customtailored" activities, being personalized rather than a general tourism offer. Increasingly, customers create their own experiences and personalize the places they wish to visit. Tourists are prosumers - responsible for many of their own goods and services [2]; this phenomenon is strongly boosted by the technological development we are witnessing today.

This type of applications targets the tourist and not the resident, although both benefit from the process. Meaning, it fits both the tourist and resident, changing according to the need, but serving everyone; always working towards the satisfaction of tourists and improving the quality of life of residents.

These smart guides exemplify one of 2018's trends, according to TrendWatching assisted development, since they provide its users with behavioural guidelines and 
accessibility of information. An example of an application that produces travel guides in a mobile format with content culturally adapted to the tourist is the JiTT.travel. It offers a customized high-quality experience, transforming users' smartphones into smart tourist guides, giving inputs based on their desired journey according to current location and available time frame to be spent in each location. It is absolutely free and comes with a huge feature: it works offline! It was nominated by World Tourism Association as the "best mobile application designed to enrich tourists' experience" [4], working alongside the tourism development market and taking advantage of the growing need to serve tourists.

\section{Methodology}

To evaluate the general awareness on smart cities and smart tourism as contemporary topics, a questionnaire and a focus group session were conducted. The questionnaire, public and anonymous, contained around twenty questions, split into two different sections (see Table 1). The first section was related to personal data, with closed questions, and the second section was referring to the analysed theme.

Table 1. Questions and answers of the questionnaire.

\begin{tabular}{|c|c|}
\hline Question & Summary of the answers \\
\hline $\begin{array}{l}\text { Do you agree on applying new technologies in } \\
\text { tourism? }\end{array}$ & $\begin{array}{l}\cdot 94.9 \% \text { - Agree } \\
\cdot 5.1 \% \text { - Do not agree }\end{array}$ \\
\hline Why? & $\begin{array}{l}\text { Innovation, less third-party dependencies, } \\
\text { better experience, easier to access and } \\
\text { accessible at any time }\end{array}$ \\
\hline Do you know any smart tourism applications? & $\begin{array}{l}\cdot 17.7 \%-\text { Yes } \\
\cdot 82 \%-\text { No }\end{array}$ \\
\hline $\begin{array}{l}\text { Have you ever used any of the applications } \\
\text { you know? }\end{array}$ & $\begin{array}{l}-\rightarrow \text { out of the } 17.7 \% \text { that know any } \\
\text { application: } \\
\cdot 20.4 \% \text { - Yes } \\
-79.6 \% \text { - No }\end{array}$ \\
\hline $\begin{array}{l}\text { Have you ever heard that tourism may be } \\
\text { replaced with virtual reality? }\end{array}$ & $\begin{array}{l}\text { - } 51.9 \% \text { - Yes } \\
\text { - } 48.1 \% \text { - No }\end{array}$ \\
\hline Which one do you prefer? & $\begin{array}{l}\text { - } 20.9 \% \text { - Virtual reality guidance } \\
\text { - } 79.1 \% \text { - Human guidance }\end{array}$ \\
\hline Why (Virtual reality guidance)? & $\begin{array}{l}\rightarrow \text { out of } 20.9 \% \text { that prefer virtual reality } \\
\text { guidance: } \\
\text { Cost efficiency, privacy, no third-party } \\
\text { dependencies }\end{array}$ \\
\hline Why (Human guidance)? & $\begin{array}{l}\rightarrow \text { out of } 79.1 \% \text { that prefer human guidance: } \\
\text { Employment stability, human interaction, } \\
\text { cultural experience }\end{array}$ \\
\hline
\end{tabular}


Table 1. (continued)

\begin{tabular}{l|l}
\hline Question & Summary of the answers \\
\hline $\begin{array}{l}\text { In your personal opinion, does virtual reality } \\
\text { guidance impact tourism positively or } \\
\text { negatively? }(*)\end{array}$ & $\bullet 39.2 \%$ - Negatively \\
\hline Why (negatively)? & $\begin{array}{l}\rightarrow \text { out of } 39.2 \% \text { that said it negatively } \\
\text { impacts: }\end{array}$ \\
& $\begin{array}{l}\text { Unemployment, may not be qualified to } \\
\text { personal requirements, no human/cultural } \\
\text { interaction }\end{array}$ \\
\hline Why (positively)? & $\begin{array}{l}\text { Availability, cost efficiency, multi-language, } \\
\text { the guidance given may support profile } \\
\text { customization }\end{array}$ \\
\hline $\begin{array}{l}\text { Would you use virtual guidance if } \\
\text { recommended by any friend/family? }\end{array}$ & $\begin{array}{l}\cdot 25.4 \% \text { - I would } \\
10.2 \% \text { - I would not }\end{array}$ \\
\hline $\begin{array}{l}\text { Do you know any location using smart } \\
\text { tourism technologies? }\end{array}$ & $\bullet 64.3 \%$ - Probably \\
\hline
\end{tabular}

(*) - Yes or no question to gather information on which side people would support more (positive or negative impact). Giving no neutral option to further discuss choices made.

Distinguishing between gender, age and education qualifications was crucial in order to identify common patterns. That was the first part of the study. Being more generalistic, composed by both closed and open questions, the second section provided some insight on subjects such as common knowledge on the smart tourism topic and community willingness to embrace new technologies in tourism.

\subsection{Summary of the Field Work}

Table 1 shows a summary of the questionnaire questions and answers (176 valid answers were received). We can see that technology and tourism are closely linked, in the perspectives of the respondents, and in effect there has been a very significant boom in tourism due also to technology. Albeit, most respondents (82\%) do not know any smart tourism applications. Furthermore, the sample is divided on whether "tourism may be replaced with virtual reality?" Human guidance and human interaction are much preferred over virtual reality $(79.15 \%)$, though virtual reality guidance is seen to impact tourism positively $(60.8 \%)$. Virtual reality is seen to lead to unemployment, a negative effect. As concerns the question "Would you use virtual guidance if recommended by any friend/family?", $25.4 \%$ would, and $64.3 \%$ probably would - which shows the receptivity to this sort of technology.

Relatively to the focus group (see Table 2), we had the pleasure to set up a session with João Costa and Diogo Correia, who welcomed us at Ubiwhere. 
Table 2. Information about the interviewees in the focus group.

\begin{tabular}{l|l|l|l}
\hline $\begin{array}{l}\text { Interviewees } \\
\text { in the focus } \\
\text { group }\end{array}$ & $\begin{array}{l}\text { Gender } \\
\text { and age }\end{array}$ & Job at Ubiwhere & Academic qualifications \\
\hline $\begin{array}{l}\text { Diogo } \\
\text { Correia }\end{array}$ & $\begin{array}{l}\text { Male, } \\
23 \\
\text { years } \\
\text { old }\end{array}$ & $\begin{array}{l}\text { Smart Cities Manager (which involves } \\
\text { developing business strategies, sales } \\
\text { management and providing insight on } \\
\text { smart cities solutions) }\end{array}$ & $\begin{array}{l}\text { Master's in Industrial } \\
\text { Engineering and } \\
\text { Management; } \\
\text { Currently a PhD student }\end{array}$ \\
\hline $\begin{array}{l}\text { João Soares } \\
\text { da Costa }\end{array}$ & $\begin{array}{l}\text { Male, } \\
30 \\
\text { years } \\
\text { old }\end{array}$ & $\begin{array}{l}\text { Marketing Manager (the goal is to make } \\
\text { Ubiwhere more attractive for customers } \\
\text { and employees alike, through a simple } \\
\text { and focused brand) }\end{array}$ & $\begin{array}{l}\text { Bachelor's degrees in } \\
\text { Public Administration and } \\
\text { Marketing; } \\
\text { MBA in Marketing } \\
\text { Management }\end{array}$ \\
\hline
\end{tabular}

The focus group was based on the following goals:

- To evaluate the relevance of related projects within organizations;

- To understand more about the user experience concerning smart technologies;

- To retain a personal point of view from people that develop technological solutions and use technology on a daily basis.

The script had six questions, discussed during the focus group meeting:

- Ubiwhere works on smart city-based solutions. Tell us more about them.

- Which cities are currently using these solutions? And where specifically are they most used (concrete locations/places)?

- Are any of the solutions connected to smart tourism?

- Do you have any thoughts on smart tourism agents?

- Pros and cons of applying technologies around cities and the challenges faced while working on such solutions?

- Opinion on "Tourism may be replaced by virtual reality".

\section{Discussion of the Fieldwork}

\subsection{Questionnaire}

The questionnaire had a clear input on how people in general are likely to embrace new technologies around their cities. Despite it being noticeable how new this topic is in the community, the majority tend to accept and support its positive impacts.

The $45+$ year-old public were the only ones with a full acceptance rate $(100 \%)$ in the questionnaire, accepting new technologies in their cities and in tourism itself with more ease. Furthermore, every one of them stated that they did not know any smart tourism applications, nor have they used any, which led us to retain that people with the most willingness to accept and acknowledge existing applications are not the ones using them the most - there was no direct relationship. 
Generation X, which is now between 30 and 45 years old, tends to be less willing to embrace new changes, even though this trend is also changing [23]. Having been born and having grown up along major technological development, generation $\mathrm{X}$ is known for its human interaction and multi-tasking qualifications. Living for work, family and friends, this generation embraces with more ease applications on related subjects.

Since gender was not as revealing as age, qualifications were also taken into consideration for further analysis. Unfortunately, no particular patterns were found.

It is clear how the community understands the statement "Have you ever heard that tourism may be replaced with virtual reality?", being totally divided (nearly 50\%/50\%). Furthermore, it is unanimous that a real person is preferred to serve as a guide rather than having virtual guides. People still need to relate to other people. Empathy, culture and specifically human contact along with a noticeable dismay by an increase in unemployment were mentioned.

While trying to understand if people, even those with none or minimal knowledge on the subject, were more likely to start using smart applications, if suggested by friends and family, it was noticed that even when suggested by the closest friends or relatives, there is still a "maybe" on the lips of the majority, affirming just how new and fresh the concept still is.

\subsection{Focus Group}

Considered a "Bleeding Edge Technologies" [17] organization and founded in 2007, Ubiwhere has been growing ever since. Their headquarters are currently in Aveiro, having moved there in 2017. They also may be found in Porto, Coimbra and even in Lisbon. Ubiwhere mainly provides smart cities and telecommunications solutions.

Related to smart cities, they are currently working on areas such as waste management, smart guides for wineries and wine exhibitions, and museums and parking traffic management. A wide variety of solutions are available for locations such as Guimarães, Aveiro and Porto. Note that one of their solutions for waste management, implemented in Aveiro, named PAYT (Pay as you Throw) [18], tends to support reducing taxes around communities that promote waste recycling. The more a user recycles, the less waste tax he will be paying, improving the environment and reducing individual expenses by doing good.

João and Diogo share a common opinion that smart cities solutions, being related to the improvement of the community experience while living in the city, and smart tourism solutions, aiming to improve the community experience going in and out of a city, are strongly connected. Both concepts are related, supporting each other directly or indirectly.

It was also impressive how professionals, who improve, use and work with technologies on a daily basis state that "Human interaction cannot be replaced". Both support technology usage and acceptance worldwide, but both think that culture is still of major value to the users' experience, not believing in the statement that "Tourism may be replaced by virtual reality". The simple act of taking a photo, human interaction and even the use of Google maps while connecting with people during a trip seem irreplaceable in the near future, and this can only strengthen the fact that tourism experiences and experiences in general should be "personal experiences" and not 
generalized. However, benefits such as cost efficiency and bringing tourism to everyone - the poor, the rich, the able and the disabled - were also mentioned.

As referred to and concluded at the smart cities congress during Techdays Aveiro 2018 [19], the biggest obstacles remain as being financing and political support. Having both, the last challenge will be obtaining community support, which is inevitable since such solutions will bring major benefits to the city. João, who was present at the congress, also mentioned that they themselves share these concerns, but consider - both being very positive individuals - that it is only "a matter of time" until they are overcome.

\section{Conclusions and Suggestions for Future Research}

With today's technological advancement, the population growth of cities (as illustrated in Graphic 1) and the subsequent natural resource shortage have given rise to the need to restructure some processes in order to efficiently manage available resources.

The smart cities concept presents itself as a viable answer aiming to support the restructuring of these processes, focusing on smart mobility, smart economy, smart people, smart governance, smart environment and smart living (as illustrated in Fig. 1). Being a relatively new concept and still rather less-known, cities are investing more often in related solutions, Sharing Cities [6, 7] and Aveiro Steam City [20] holding €24 million and $€ 6.1$ million in investments, respectively. Obtaining funds is still the major obstacle to be overcome, since such investments do not cover every focus point of the smart cities concept. Although just in the phase of initial investment, it will generate additional mid- and long-term funds resulting in higher sustainability levels, governance and living quality around cities.

An application of smart cities is smart tourism, which is subtracted from the smart living concept (as illustrated in Fig. 1). As smart living is related to the experience of living in the city, smart tourism, on the other hand, is related to the experience of going in and out of the city. This can cause the community to become weary, mainly due to the lack of knowledge and exposure to the subject. As well as smart guides, smart tourism aims to respond to customer needs by crossing data around personal preferences and current location. People in general are not using smart tourism applications to enrich themselves but as a way to smooth their tourism experience, meaning that people still prefer human contact and the whole cultural experience. "... culture is not replaceable. Pictures are not enough.” - interviewee João Costa, October 2018, affirming that virtual reality is not going to replace tourism in a near future.

In conclusion, smart city solutions will be going ever further and they will overcome barriers such as financing and lack of political support. Although communities have a relatively low level of knowledge on the subject, exposure will be increasing, and people will embrace smart city technologies with more ease.

For future research, we suggest connecting investment in smart city solutions to tourism growth, to gather information on tourism preferences in cities using more technology. Furthermore, we need to understand smart city exposure issues and how to improve them, as well as community apprehension on technological paradigm embracement and the implication of data privacy around new solutions in smart cities. 
Acknowledgements. We would like to thank João Costa and Diogo Correia for having shared their opinions, experiences and current projects with us. Furthermore, a thank-you is due to everyone else involved in the questionnaires who contributed to a deepening of our knowledge on the subject.

This work is financed by the ERDF - European Regional Development Fund through the Operational Programme for Competitiveness and Internationalisation - COMPETE 2020 Programme and by National Funds through the Portuguese funding agency, FCT - Fundação para a Ciência e a Tecnologia within project POCI-01-0145-FEDER-031309 entitled "PromoTourVR Promoting Tourism Destinations with Multisensory Immersive Media".

\section{References}

1. Owaied, H.H., Farhan, H.F., Al-Hawamdeh, N., Al-Okialy, N.: A model for intelligent tourism guide system. J. Appl. Sci. 11, 342-347 (2011)

2. Toffler, A.: The Third Wave. William Morrow and Company, New York (1980)

3. Pena, J.: O Turismo em Portugal: Oportunidades e Desafios. Lisbon: Seminar AESE, 27 May 2002

4. JiTT.travel. https://jitt.travel/pt/. Accessed 27 Oct 2018

5. Notícias de Aveiro: 5G 'made in Aveiro' promovido com mini bus autónomo. https://www. noticiasdeaveiro.pt/5g-made-in-aveiro-promovido-com-mini-bus-autonomo/. Accessed 27 Oct 2018

6. UE - Lisboa é uma das Smart Cities que vai guiar a Europa. http://www.lisbonne-idee.pt/ p4132-lisboa-uma-das-smart-cities-que-vao-guiar-europa.html. Accessed 28 Oct 2018

7. Sharing Cities. http://www.sharingcities.eu/sharingcities/city-profiles/lisbon. Accessed 27 Oct 2018

8. Al Nuaimi, E., Al Neyadi, H., Mohamed, N., Al-Jaroodi, J.: Applications of big data to smart cities. J. Internet Serv. Appl. 6(1), 1-15 (2015). A SpringerOpen Journal

9. Manville, C., Cochrane G., Cave, J., Millard, J., Pederson J.K., Thaarup, R.K., Kottering, B.: Mapping Smart Cities in the EU. Policy Department A: Economic and Scientific Policy, European Parliament (2014)

10. Selada, C., Silva, C.: Smart Cities in the European Agenda: Opportunities for Portugal. II Conferência de PRU, VII ENPLAN e Wokshop APDR: "Europa 2020: retórica, discursos, política e prática"

11. INTELI: Índice de Cidades Inteligentes - Portugal. INTELI (2012)

12. Li, Y., Hu, C., Huang, C., Duan, L.: The concept of smart tourism in the context of tourism information services. Tour. Manag. 58, 293-300 (2017)

13. Caragliu, A., Del Bo, C., Nijkamp, P.: Smart cities in Europe. J. Urban Technol. 18(2), 6582 (2011)

14. World Urbanization Prospects - Population Division - United Nations. https://population.un. org/wup/. Accessed 06 Oct 2018

15. Guardia, S., Guardia, M.: An essay on smart tourist destinations. Revista Turismo Desenvolvimento 27(28), 1305-1314 (2017)

16. Calisto, L., Gonçalves, A.: Smart citizens, wise decisions: sustainability-driven tourism entrepreneurs. In: Carvalho, L. (ed.) Handbook of Research on Entrepreneurial Development and Innovation within Smart Cities, pp. 20-43. IGI Global, Hershey (2017)

17. Ubiwhere | Bleeding Edge Technologies with Custom Research and Development. https:// www.ubiwhere.com/. Accessed 16 Oct 2018

18. PAYT - Portugal. http://www.payt-portugal.com/. Accessed 20 Oct 2018 
19. Techdays. Building our Future. https://www.techdays.pt/pt/techdays. Accessed 30 Oct 2018

20. Aveiro futurista. Dos moliceiros elétricos ao $5 \mathrm{G}$, a cidade já quer ser mais que a 'Veneza de Portugal' - Tecnologia - SAPO 24. https://24.sapo.pt/tecnologia/artigos/a-aveiro-futuristados-moliceiros-eletricos-ao-5g-a-cidade-ja-quer-ser-mais-que-a-veneza-de-portugal. Accessed 30 Oct 2018

21. Gretzel, U., Koo, C., Sigala, M., Xiang, Z.: Special issue on smart tourism: convergence of information technologies, experiences, and theories. Electron. Mark. 25(3), 175-177 (2015)

22. SEBRAE: Destinos Turísticos Inteligentes - Tecnologias de Informação e Desenvolvimento Sustentável. SEBRAE (2016)

23. The New York Times: Generation X More Addicted to Social Media Than Millennials, Report Finds. https://www.nytimes.com/2017/01/27/technology/millennial-social-mediausage.html. Accessed 29 Oct 2018

24. Climate Change - UN-Habitat for a Better Urban Future. https://unhabitat.org/urban-themes/ climate-change/. Accessed 06 Oct 2018

25. Martins, J., Gonçalves, R., Branco, F., Barbosa, L., Melo, M., Bessa, M.: A multisensory virtual experience model for thematic tourism: a Port wine tourism application proposal. J. Destin. Mark. Manag. 6, 103-109 (2017) 